\title{
CORNER EFFECTS IN DEEP EXCAVATIONS-ESTABLISHMENT OF A FORECAST MODEL FOR TAIPEI BASIN T2 ZONE
}

Chao-Hui Wu

Department of Civil Engineering, Ching-Yun University, Taiwan R.O.C, cfwu@cyu.edu.tw

Chang-Yu Ou

Department of Construction Engineering, National Taiwan University of Science and Technology, Taiwan, R.O.C

Ningchien Tung

Department of Civil Engineering, Ching-Yun University, Taiwan R.O.C

Follow this and additional works at: https://jmstt.ntou.edu.tw/journal

Part of the Civil and Environmental Engineering Commons

\section{Recommended Citation}

Wu, Chao-Hui; Ou, Chang-Yu; and Tung, Ningchien (2010) "CORNER EFFECTS IN DEEP EXCAVATIONS-

ESTABLISHMENT OF A FORECAST MODEL FOR TAIPEI BASIN T2 ZONE," Journal of Marine Science and Technology.

Vol. 18: Iss. 1, Article 1.

DOI: $10.51400 / 2709-6998.1859$

Available at: https://jmstt.ntou.edu.tw/journal/vol18/iss1/1

This Research Article is brought to you for free and open access by Journal of Marine Science and Technology. It has been accepted for inclusion in Journal of Marine Science and Technology by an authorized editor of Journal of Marine Science and Technology. 


\title{
CORNER EFFECTS IN DEEP EXCAVATIONS - ESTABLISHMENT OF A FORECAST MODEL FOR TAIPEI BASIN T2 ZONE
}

\author{
Chao-Hui Wu*, Chang-Yu Ou**, and Ningchien Tung*
}

Key words: Taipei Basin, deep excavation, wall deformation, ground settlement.

\begin{abstract}
This study attempts to establish a novel model for forecasting wall deformation and ground surface settlement of deep excavations. The model is developed by considering the corner effect and examining the data from relevant case histories. The study is specifically limited to the construction works in the T2 zone of the Taipei Basin.

The following results were obtained: (1) The maximum wall deformation during each excavation step was approximately $0.2 \%-0.5 \%$ of the excavation depth, and was influenced by the corner effect. (2) The maximum ground surface settlement took place approximately at the center of the wall; and settlements at the corners were smaller due to the corner effect, they were generally $20 \%-60 \%$ of the maximum settlement. (3) The area within a distance of two times the excavation depth had a relatively large settlement or relatively steep slope of settlement trough, which can be defined as the primary influence settlement area. The area at a distance of 2-3 times the excavation depth had a gentler slope of settlement trough and can be defined as the secondary influence settlement area. (4) If the analysis is carried out with theoretical hydrostatic pressure or with measured water pressure, the same tendency "the deeper the wall embedment depth, the greater the factor of safety for overall stability" is found.

This study also makes two specific contributions. First, the corner effects in deep excavations are further confirmed through more case studies. Secondly, a simple hazard analysis for estimating settlements induced by deep excavations is presented.
\end{abstract}

\section{INTRODUCTION}

Deep excavations release stresses in the earth and redis-

Paper submitted 03/18/08; accepted 12/13/08. Author for correspondence: Chao-HuiWu(e-mail: cfwu@cyu.edu.tw).

*Department of Civil Engineering, Ching-Yun University, Taiwan R.O.C. **Department of Construction Engineering, National Taiwan University of Science and Technology, Taiwan, R.O.C. tribute these stresses causing deformation. The soil from behind a deforming wall moves with the wall, which leads to settlement of the ground surface. Obviously, the amount of ground settlement is closely related to that of wall deformation. Factors affecting wall deformation should also influence ground settlement. From the characteristics of excavation, we can understand factors such as excavation depth, width, wall stiffness, strut stiffness and preload, factor of safety against basal heave, soil properties and so on will affect the wall deformation or ground settlement.

Since different foundation construction methods implicitly imply different wall-retaining systems, they should have significant influences on movement. Top-down construction methods and bottom-up construction methods are two main basement construction methods. Bottom-up construction methods employ temporary steel struts to balance the lateral pressure on the excavation wall while top-down construction methods apply concrete floor slabs to resist the lateral earth pressure. Since these two methods apply different retaining systems, resulting in different engineering behaviors, this study will investigate the relationship between deformation behavior and construction methods, based on the case histories.

Push-in and basal heave are two main failure modes for excavations. Mana and Clough [6] found that wall deformation decreases when the safety factor against basal heave increases. Clough and O'Rourke [4] further established a dimensionless chart describing the relationship between maximum wall movements and factors of safety against basal heave and stiffness of retaining systems. More case histories are certainly needed to examine the relationship. In addition, few studies in literature regarding the relationship between factors of safety against push-in and movement are available.

Ou et al. [7] performed a series of three-dimensional excavation analyses utilizing the three-dimensional finite element method and investigated the features of three-dimensional excavation behaviors. Close relationships existed between the aspect ratio for excavation geometry $(B / L)$ and wall deformation. Increasing the $\mathrm{B} / \mathrm{L}$ decreases the wall deformation. In addition, wall deformation of a deep excavation is directly related to the distance from the corner $(d)$ : the smaller the value of $d$, the less the wall deformation. Furthermore, Ou 
et al. [7] performed extensive parametric studies on the basis of a hypothetical case with different lengths of the primary wall $(L)$ and the complementary wall $(B)$ and established the relationship between maximum wall deformation and aspect ratio of excavation geometry. The result was verified by an actual case history. More case histories are certainly required to make concrete verification.

Some investigators have proposed, according to case studies, empirical and semi-empirical procedures for forecasting the extent of ground surface settlement and its distribution pattern because theories cannot predict the settlement effectively. Similar formulas have been developed for excavations in Taiwan and room exists for improvement, especially for the consideration of corner effects.

This study collected and investigated data of deep excavation case histories without ground improvement in the Taipei Basin T2 Zone. These excavations are characterized according to excavation wall type, wall thickness, excavation depth, wall length, wall deformation, ground surface settlement and corner effect. Charts and tables for future forecasts are made by utilizing the soil data from all cases.

\section{DESCRIPTION OF SUBSOIL PROFILES AND CASE HISTORIES}

The geological stratum beneath the Taipei basin is alluvium over a gravel layer. The alluvium is composed of six layers, where the first, third and fifth layers are silty sand while the second, fourth and sixth layers are silty clay, forming a sandwiched geological structure with an alternating stratum of both silty sand and silty clay soil deposits. The thickness of each layer demonstrates a more advanced regularity with a further distinguishing layer separation at the center of the basin, but such a distinguishing layer of separation is disordered at areas near the edge of the basin.

Due to the various depositional features of different rivers, thicknesses of the alluviums differ within the Taipei Basin. The ten case histories illustrated in this study are located in Zone T2, near the Tamshui river and a sub zone of the Taipei basin, where the soil profile exhibits six distinguishingly alternating layers of sand and clay deposits. The fourth layer, silty clay, in this zone, is approximately 5-10 meters thick while the fifth and third layers are relatively thick, around 15-20 meters thick. Generally, sandy layers become thicker when closer to the river while clay layers are thinner. The gravel stratum in this zone is about 40-50 meters below the ground surface. Table 1 summarizes the typical characteristics of each layer. More information regarding the properties of the soils in the $\mathrm{T} 2$ zone of the Taipei basin can refer to Cheng [3], Wu [15], and Hulme et al. [5].

This study gathered ten typical excavation case histories in the zone that utilized slurry walls as retaining structures for their foundation excavation; seven cases used open-cut, inner braced, bottom-up excavation techniques while three cases used top-down methods. Figure 1 illustrates the excavation
Table 1. Typical characteristic for each stratum of the Taipei Basin.

\begin{tabular}{ccl}
\hline $\begin{array}{c}\text { Geological profile } \\
\text { (Start from the } \\
\text { ground surface })\end{array}$ & $\begin{array}{c}\text { Stratum } \\
\text { thickness } \\
(\mathrm{m})\end{array}$ & Description of soil characteristics \\
\hline Sixth stratum & $3-8$ & $\begin{array}{l}\text { Yellow-brownish top soil with } \\
\text { gray-black silt. } \omega=30-35 \%\end{array}$ \\
\hline Fifth stratum & $15-20$ & $\begin{array}{l}\text { Gray silty sand, even granular, with } \\
\text { 30-40\% silty fine. }\end{array}$ \\
\hline Fourth stratum & $5-10$ & $\begin{array}{l}\text { Gray silty clay with a sand content of } \\
\text { less than 10\%. }\end{array}$ \\
\hline Third stratum & $15-20$ & $\begin{array}{l}\text { Yellow-grayish plastic, silty fine is } \\
25 \%, \omega=25 \%\end{array}$ \\
\hline Second stratum & $0-19$ & $\begin{array}{l}\text { Grayish silty clay, medium com- } \\
\text { pacted soil with a medium to low } \\
\text { plasticity. Silty fine } F=45-70 \%, \\
\omega=25 \%\end{array}$ \\
\hline First stratum & $0-15$ & $\begin{array}{l}\text { Medium-to-compact gravelly sand } \\
\text { with a fine content of } 20 \% \text { in general } \\
\text { or slightly higher. }\end{array}$ \\
\hline
\end{tabular}

$\omega$ : natural water content
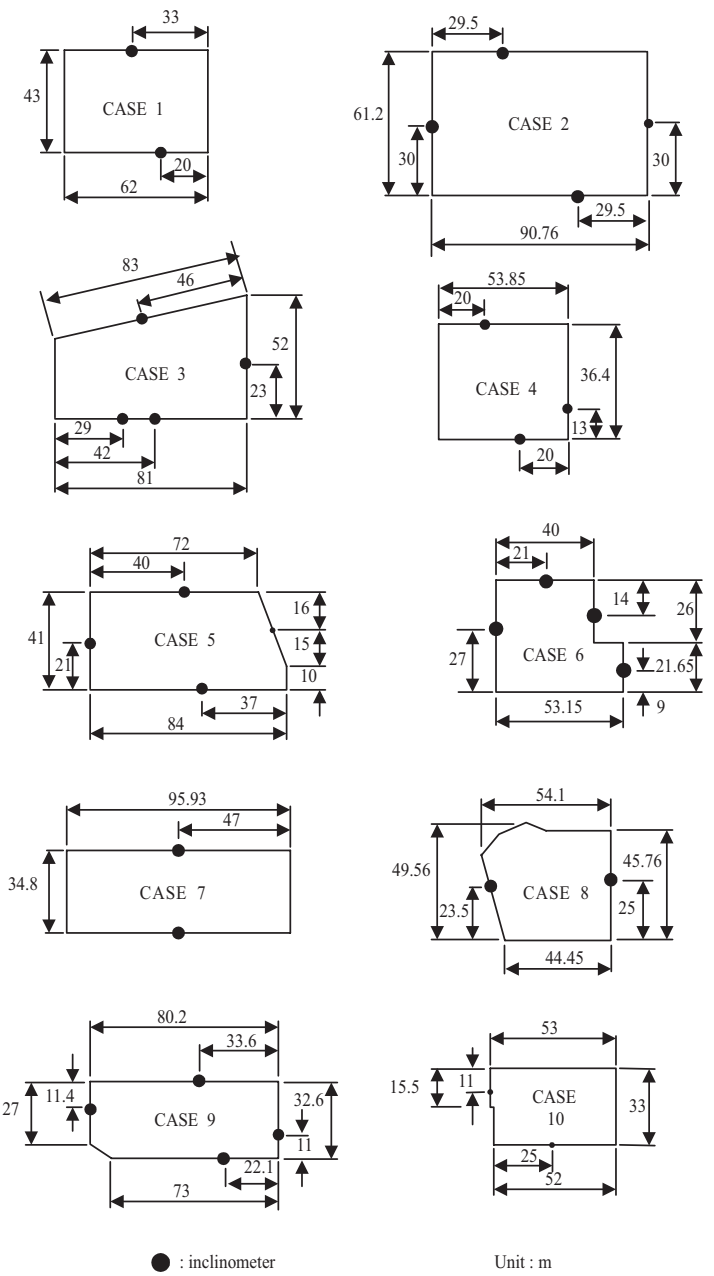

Fig. 1. Layout of excavation geometry and positions of inclinometer of the analyzed case. 

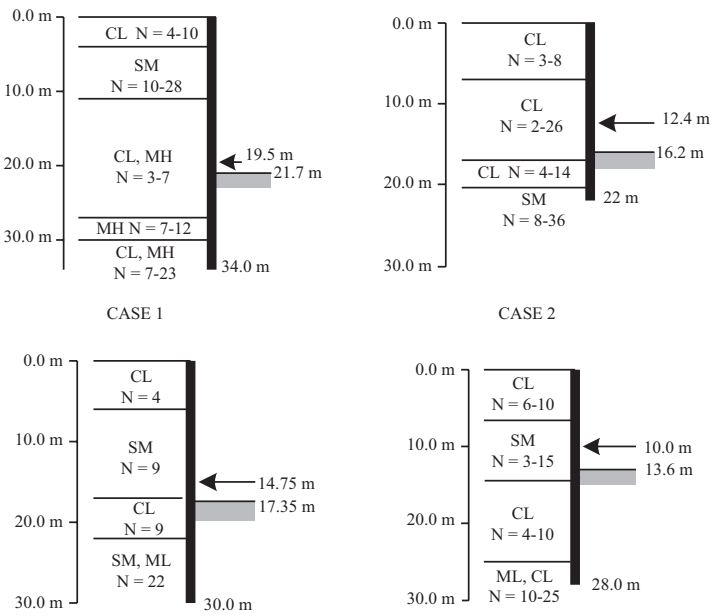

CASE 3

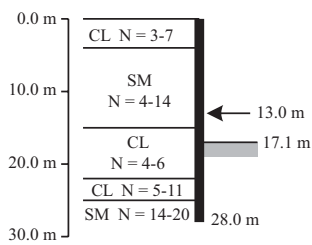

CASE 5

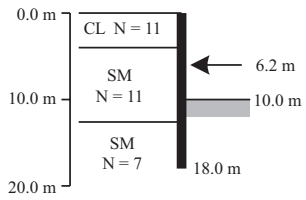

CASE 7

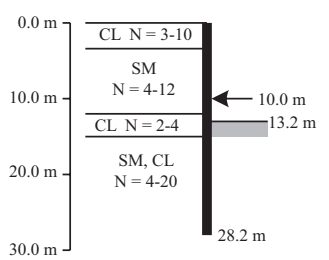

CASE 9

$$
\begin{aligned}
& \text { The walls } \\
& \text { The final support } \\
& \text { The final excavation }
\end{aligned}
$$

Fig. 2. Soil profiles and position of final supports in studied cases.

shape and locations of monitoring instruments for wall deformation and Fig. 2 presents the excavation profile along with soil profile for each case history. Table 2 lists the construction procedures, description of geology and basic excavation data, and soil profiles of the case histories.

\section{SPECIAL CONSIDERATIONS IN THE ANALYSES}

\section{Corner Effect}

Ou et al. [7] established the relationship between plane
Table 2. Basic data for excavation case histories.

\begin{tabular}{c|c|c|c|c|c|c|c|c}
\hline & & \multicolumn{3}{|c|}{ Diaphragm wall data } & \multicolumn{4}{|c}{ Site geometry data } \\
\cline { 4 - 10 } Case & $\begin{array}{c}\text { Method of } \\
\text { excavation }\end{array}$ & $\begin{array}{c}H \\
(\mathrm{~m})\end{array}$ & $\begin{array}{c}t \\
(\mathrm{~cm})\end{array}$ & $\begin{array}{c}\delta_{h, \mathrm{max}} \\
(\mathrm{mm})\end{array}$ & $\begin{array}{c}L \\
(\mathrm{~m})\end{array}$ & $\begin{array}{c}B \\
(\mathrm{~m})\end{array}$ & $\begin{array}{c}H_{e} \\
(\mathrm{~m})\end{array}$ & $\begin{array}{c}\text { Number of } \\
\text { excavation } \\
\text { stages }\end{array}$ \\
\hline A & B-U & 34.0 & 70 & 6.67 & 62 & 43 & 21.70 & 8 \\
\hline B & B-U & 22.0 & 70 & 7.96 & 91 & 61 & 16.20 & 5 \\
\hline C & T-D & 30.0 & 80 & 10.50 & 82 & $34 \sim 42$ & 17.35 & 4 \\
\hline D & T-D & 28.0 & 70 & 5.40 & 54 & 36.5 & 13.60 & 4 \\
\hline E & B-U & $28 ~ 30$ & 80 & 5.25 & 84 & 41 & 17.10 & 6 \\
\hline F & B-U & 28.0 & 70 & 4.40 & $40 \sim 53.5$ & $22 \sim 48$ & 12.50 & 4 \\
\hline G & B-U & 18.0 & 60 & 1.67 & 96 & 35 & 10.00 & 4 \\
\hline H & B-U & 21.5 & 60 & 4.52 & 54 & 46 & 12.60 & 5 \\
\hline I & T-D & 28.2 & 70 & 7.40 & 80 & 32 & 13.20 & 4 \\
\hline J & B-U & 23.0 & 60 & 4.47 & 53 & 33 & 11.40 & 4 \\
\hline
\end{tabular}

T-D: Top - down method B - U: Bottom - up method

$H$ : Wall depth $t$ : Wall thickness $\delta_{h \text {, max }}$ : Max. wall deformation

$L$ : Length $\quad B$ : Width $\quad H_{e}$ : Excavation depth

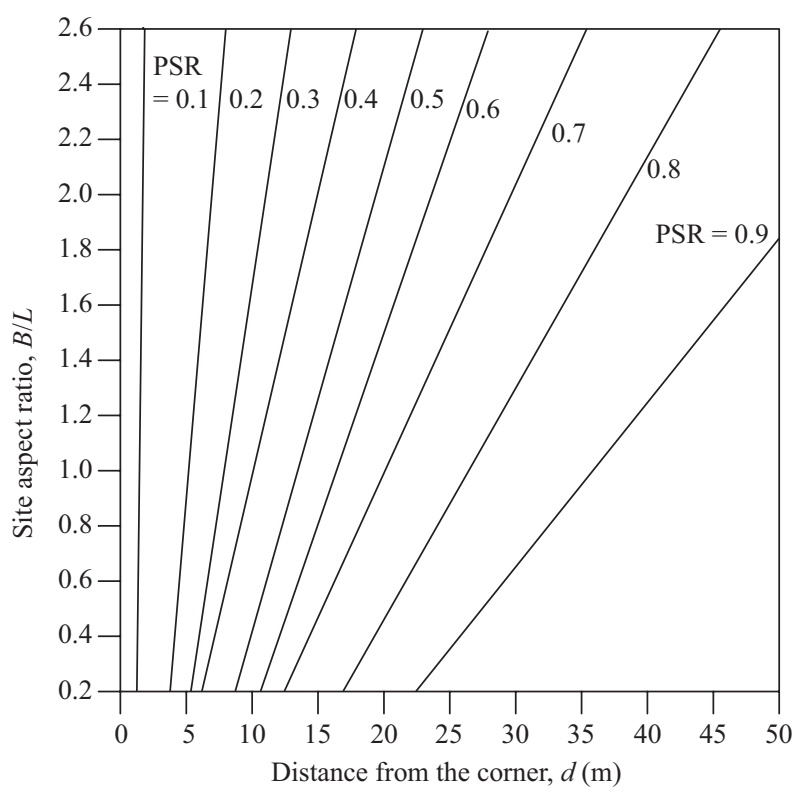

Fig. 3. Relation between plane strain ratio (PSR) and site aspect ratio $(B / L)$ and distance from the corner $(d)[7]$.

strain ratio (PSR) and $(B / L)$ and $d$ (distance from corner) based on the results of parametric studies, as shown in Fig. 3. PSR is defined as the ratio of the maximum wall deformation of the cross section at $d\left(\delta_{h}\right)$ to the maximum wall deformation in the plane strain conditions of the same geometry $\left(\delta_{p s}\right)$, i.e., PSR $=$ $\delta_{h} / \delta_{p s}$, as shown in Fig. 4. Higher values of PSR represent sections that are less affected by the corner. The section is in a plane strain condition when PSR equals 1.0. This study utilizes Fig. 3 and PSR to verify if the wall of an excavation is in a plane strain condition. 

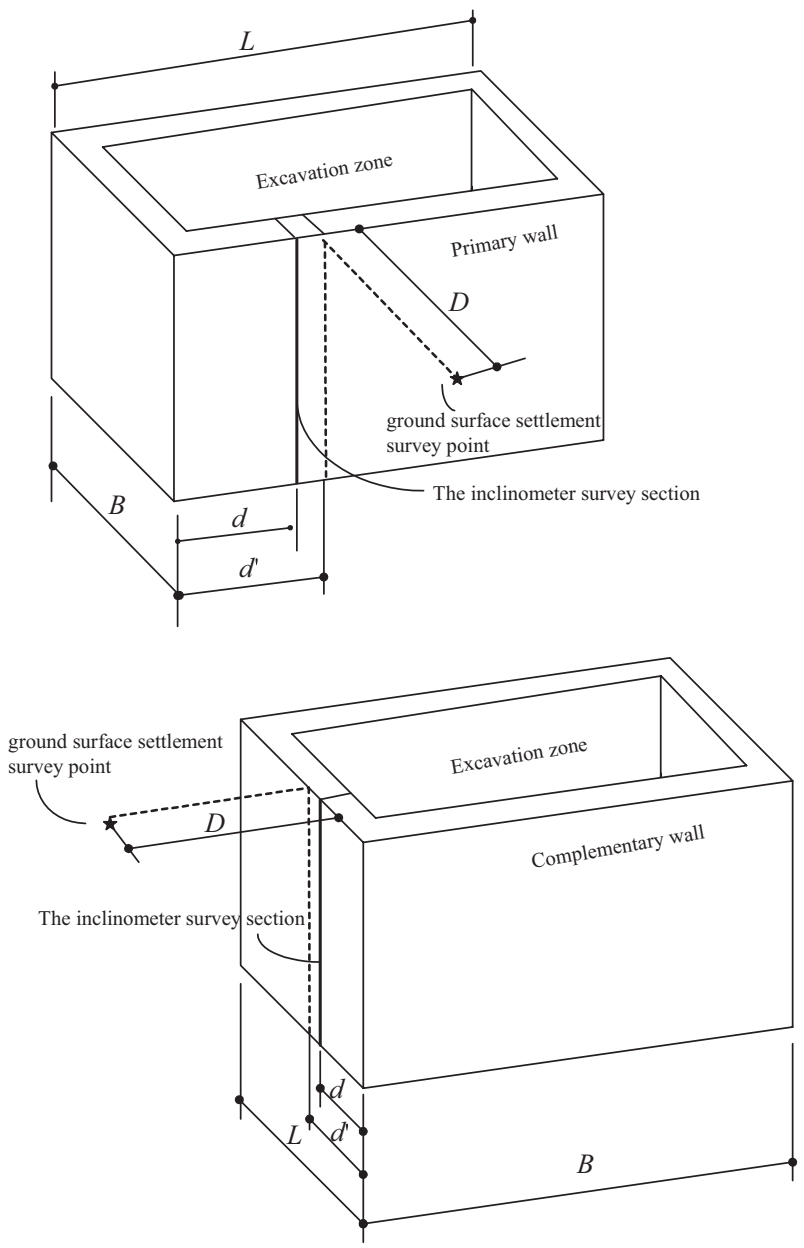

Fig. 4. Configurations of the notation of the PSR, $B, L$, and $d$.

Inclinometers are usually installed at the periphery of the excavation in a typical excavation, which does not necessarily locate at the center of the wall. The wall deformation behavior at the inclinometer position is therefore not necessary at a plane strain status and all depends on the relations between the aspect ratio for excavation geometry $(B / L)$, the distance from the corner $(d)$ and the thickness of the wall $(t)$.

Though Fig. 3 was verified by an actual case history, it may still contain some inaccuracies because it was established purely based on an assumed excavation condition and numerical studies. Considering that most of excavations may not always be in the plane condition, even though the inclinometers are placed at the center of the wall, their PSR may not be equal to 1.0. Therefore, we assume that when the magnitude of PSR is equal to or greater than 0.8 , i.e., PSR $\geq 0.8$, the walls where the inclinometers are installed are in the plane strain condition. Thus, the way to determine whether the position of the inclinometer is in a plane strain status is to first determine the $B / L$ and $d$ values at the cross section where the inclinometer located. Then determine their corresponding positions in Fig. 3 and see whether the corresponding PSR values are equal to or greater than 0.8 . This study considers the fol-
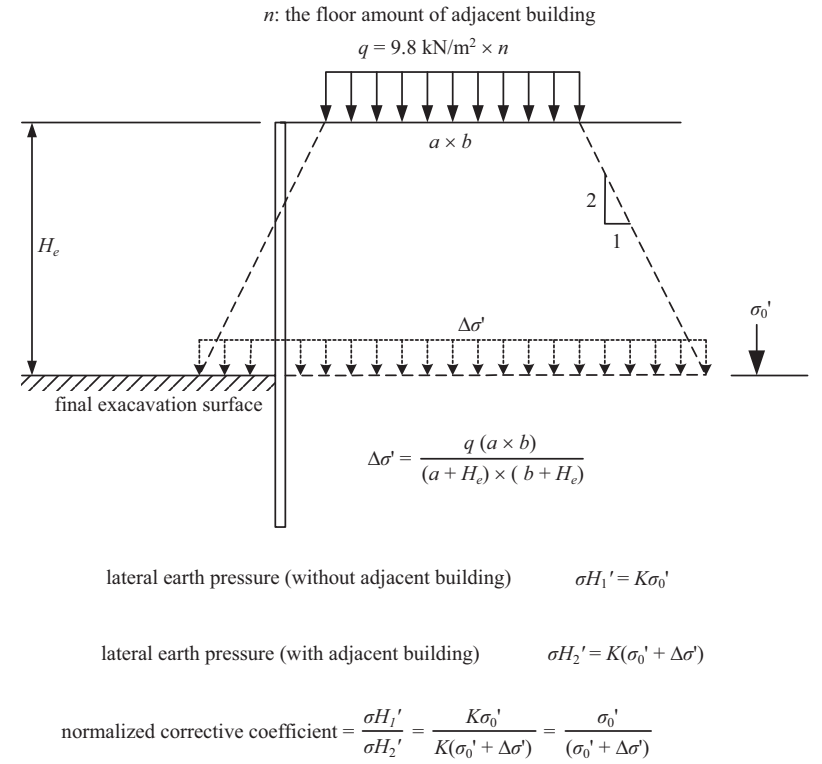

Fig. 5. The normalized corrective coefficient of adjacent building.

lowing conditions to determine the PSR values of each lateral deformation observation tube of the wall:

(1) Should a cross section of $B / L$ and $d$ value correspond in Fig. 3 with a PSR $\geq 0.8$, then the maximum wall deformation of that cross section is set to $\delta_{p s}$. The maximum wall deformation of another cross section in the site is set as $\delta_{h}$, then the real plane strain ratio should be PSR $=$ $\delta_{h} / \delta_{p s}$

(2) If all the inclinometer positions correspond to Fig. 3 with PSR values less than 0.8 , then the value of $\delta_{p s}$ is absent and therefore the real PSR values of other positions cannot be calculated, and hence data of that site is not utilized by this study at all.

\section{Load of Adjacent Buildings}

Adjacent buildings at different locations in each individual case history have different influences on an excavation compared to a site with an open surrounding. From statistics of the observed results in this study, the wall deformations in a site with adjacent buildings tend to be larger.

This study assumes that a surcharge of $9.81 \mathrm{kN} / \mathrm{m}^{2}$ for each floor of the neighboring buildings act on the ground surface, which will be spread to the depth of excavation bottom by a ratio of one horizontal to two vertical. $\sigma_{0}{ }^{\prime}$ and $\sigma^{\prime}$ denote the effective overburden pressure at and the increment due to surcharge acting on the depth of the excavation bottom. Figure 5 shows the proportional corrective coefficient of lateral earth pressure $\left(K \sigma_{0}{ }^{\prime} / K\left(\sigma_{0}{ }^{\prime}+\sigma^{\prime}\right)\right)$. Since this is a proportional relation, the coefficient of lateral earth pressure $K$ in the formula will be canceled in both the numerator and the denominator, thus yielding $\left(\sigma_{0}{ }^{\prime} /\left(\sigma_{0}{ }^{\prime}+\sigma^{\prime}\right)\right)$ as the normalized corrective coefficient. (See Fig. 5) 


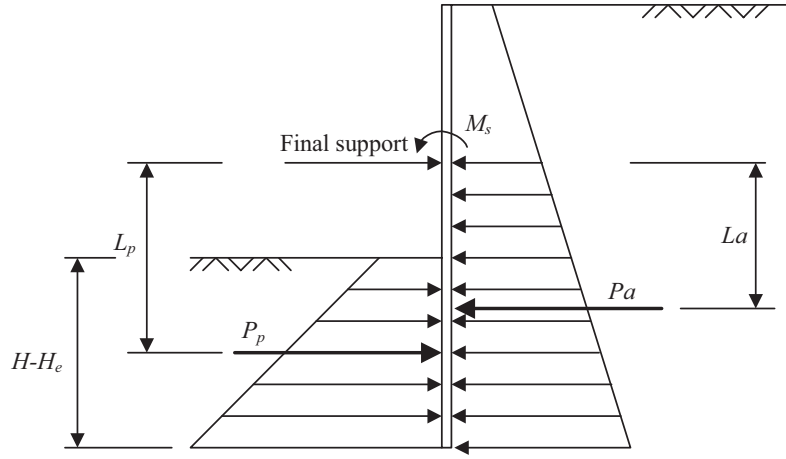

Fig. 6. Factor of safety against push-in $\left(F_{p}\right)$.

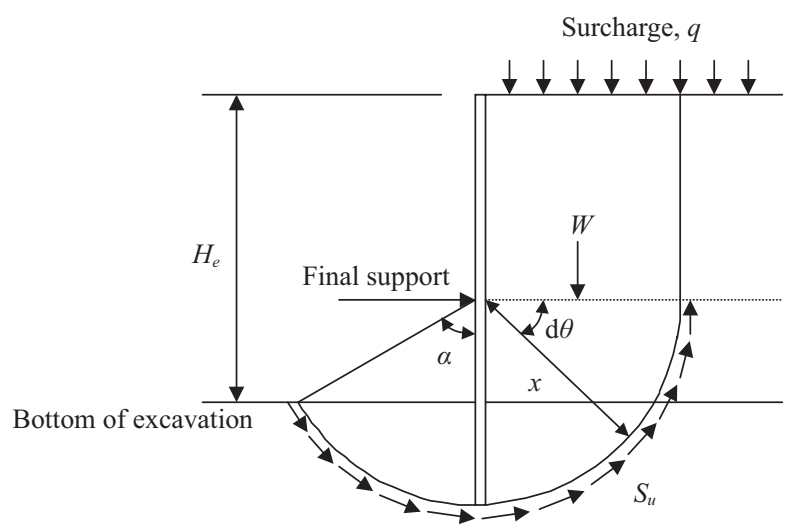

Fig. 7. Factor of safety against basal heave $\left(F_{b}\right)$.

This study identified the magnitude of lateral deformation of the walls at the position with adjacent buildings. Next, the effective overburden pressure on the excavation bottom $\sigma_{0}{ }^{\prime}$ and stress increment $\sigma^{\prime}$ due to the adjacent buildings were calculated, respectively. Finally, the lateral wall deformation measurement was connected by multiplying the normalized corrective coefficient $\left(\sigma_{0}{ }^{\prime} /\left(\sigma_{0}{ }^{\prime}+\sigma^{\prime}\right)\right)$. After correction, all cases can be treated on the same basis as if there was no adjacent building.

\section{Factors of Safety for Overall Stability}

The push-in and the basal heave failures are the two main overall failure modes of excavations. According to Fig. 6, the push-in failure is caused by the earth's pressure, reaching the limiting state, on both sides of the excavation wall, which is thereby mainly moved toward the excavation zone (especially the part embedded in the soil) until leading to the full-zone failure. The analysis views the excavation wall as a free body and the external forces on the wall and internal forces of the wall are in equilibrium. Calculating the factor of safety against the push-in failure follows:

$$
F_{p}=\frac{P_{P} L_{P}}{P_{A} L_{A}-M_{s}}
$$

where $F_{p}=$ factor of safety against push-in; $P_{a}=$ resultant of the active earth pressure on the outer side of the wall below the lowest level of strut; $L_{a}=$ length from the lowest level of strut to the point of action $P_{a} ; M_{s}=$ allowable bending moment of the excavation wall; $P_{p}=$ resultant of the passive earth pressure on the inner side of the excavation wall below the excavation surface; $L_{p}=$ length from the lowest level of strut to the point of action $P_{p}$.

The basal heave failure arises from the weight of soil outside the excavation zone exceeding the bearing capacity or the shear strength of soil below the excavation bottom, causing the soil to move and the excavation bottom to heave so much that the whole excavation site collapses. Figure 7 shows a possible form of basal heave, adopted by the Japanese and Taiwanese building codes. Calculating the factor of safety against basal heave follows:

$$
F_{b}=\frac{X \int_{0}^{\pi / 2^{+\alpha}} s_{u}(X d \theta)}{W \cdot \frac{X}{2}}
$$

where $S_{u}=$ undrained shear strength of clay; $X=$ radius of the failure circle; $W=$ total weight of the soil in front of the vertical failure plane and above the excavation surface, including the surcharge on the ground surface.

Both the Japanese and Taiwanese building codes suggest that $F_{p}$ and $F_{b}$ should be equal to or greater than 1.2. According to the drilling reports of the case histories, together with the soil's basic properties (unit weight $\gamma$, water content $\omega$, specific gravity $G_{s}$ and porosity $n$ ) and soil shearing parameters $(c$ and $\phi)$, a separate calculation $F_{p}$ and $F_{b}$ for each case history was made. Sandy soils utilize effective stress analysis while total stress analysis is employed for clayey soil. A normalized value of $S_{u} / \sigma_{v}^{\prime}=0.3$, which is generally considered to be a reasonable value in the $\mathrm{T} 2$ zone, for clayey soils was utilized.

For cohesionless soils, to compute the active earth pressure on the back of the excavation wall and the passive earth pressure on the front of the wall, adopt Caquot-Kerisel's [2] earth pressure theory, because the failure surface assumed by the theory is close to the actual failure surface. According to the theory, both Caquot-Kerisel's [2] coefficients of active and passive earth pressure correlate with $\delta$ closely. Considering the process of trench excavation and concrete casting of the construction of diaphragm walls, the borders between trenches and soil are often rugged and the assumption that $\delta=\phi^{\prime}$ seems to be reasonable for sandy soils. However, to be conservative in analysis and existence of stabilizing fluid in trenches, $\delta=$ $2 \phi^{\prime} / 3$ is utilized for the active side and $\delta=\phi^{\prime} / 3$ for the passive side, respectively.

For cohesive soils, considering the existence of the adhesion between excavation walls and the soil, the earth pressures can be calculated as follows ( Padfield and Mair [10]): 


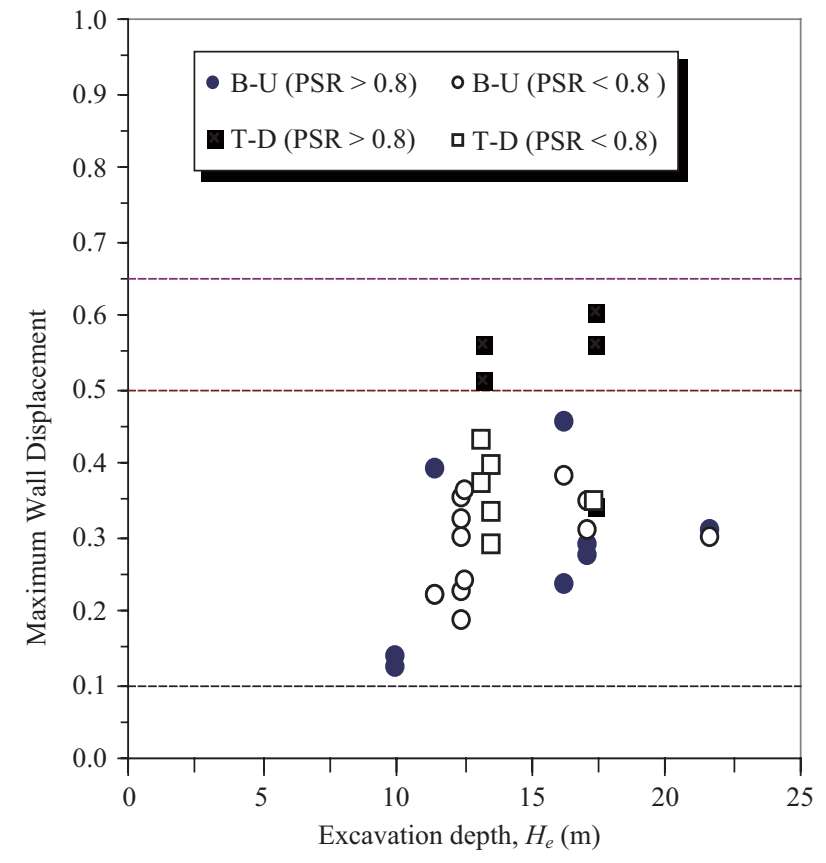

Fig. 8. Relation between the excavation wall maximum horizontal displacement $\left(\delta_{h, \text { max }}\right) /$ the excavation depth $\left(H_{e}\right)$ and the excavation depth $\left(H_{e}\right)$ of each excavation stage.

B-U (bottom-up method); T-D (top-down method).

$$
\begin{gathered}
\sigma_{a}=\sigma_{v} K_{a}-2 c K_{a c} \\
K_{a c}=\sqrt{K_{a}\left(1+\frac{c_{w}}{c}\right)} \\
\sigma_{p}=\sigma_{v} K_{p}+2 c K_{p c} \\
K_{p c}=\sqrt{K_{p}\left(1+\frac{c_{w}}{c}\right)}
\end{gathered}
$$

where $\sigma_{a}, \sigma_{p}=$ total active and passive earth pressures; $c=$ cohesion intercept; $\phi=$ angle of shear strength resistance; $c_{w}=$ adhesion between the excavation wall and soil; $K_{a}=$ coefficient of active earth pressure; $K_{p}=$ coefficient of passive earth pressure.

$\mathrm{Ou}$ and $\mathrm{Hu}$ [9] found that the adhesion $\left(c_{w}\right)$ between diaphragm walls and clay could be reasonably assumed to be 0.67 $S_{u}$ and that between steel sheet piles and clay be assumed to be $0.5 S_{u}$ for stability analysis of excavations.

\section{Water Pressure}

The excavation walls in the investigated case histories are typically implanted into silty clay and silty sand strata, and seepage from the outside excavation into the excavation zone would not occur under such circumstances. Therefore, seepage was not considered in the analysis. Accordingly, calculations on pressure distribution of pore water equal to hydro- static pressure were conducted, which are normally employed in engineering practice. For comparison, this study also utilized the actual water pressure measured at the excavation site to compute the factors of safety.

\section{CHARACTERISTICS OF WALL DEFORMATION}

\section{Depth of Excavation}

Figure 8 shows the relationship between the excavation depth $\left(H_{e}\right)$ and the ratio of the maximum wall displacement to the excavation depth $\left(\delta_{h, \max } / H_{e}\right)$. For consistency, the data at an early stage of excavation having cantilever type of wall deformation are not adopted in this study. As shown in the Fig. 8 , the values of $\delta_{h, \max } / H_{e}$ for all stages are approximately $0.2 \%$ to $0.5 \%$ for the excavations in the $\mathrm{T} 2$ zone, which mostly have a layered sandy soil and clayey soil deposit.

Additionally, observation from the chart and a comparison with the top-down and bottom-up methods reveal that at the same excavation depth, the top-down method has a tendency of producing larger wall deformations. The reason is that the top-down construction method applies the concrete floor slab to balance the lateral earth pressure whereas the bottom-up method applies the temporary steel struts. With the top-down method, considerable time is usually required to erect molds, cast concrete and wait until the concrete hardens enough. Under such circumstances, creep of soil may occur, which causes the soil to move during this period. Consequently, the top-down method causes more wall deformation than the bottom-up method.

Figure 8 reveals that the maximum wall deformation with an observed PSR $>0.8$ is generally larger than the maximum wall deformation with an observed PSR $<0.8$ regardless of what method, the top-down or bottom-up method, is utilized.

\section{Plane Strain Ratio}

As mentioned earlier, the PSR-B/L- $d$ relation chart in Fig. 3 deduces purely from theories. More case histories are required to assess the corner effects even though one case history verified the accuracy (Ou et al. [8]). Figure 9(a) shows PSR- $B / L-d$ for each case history. The PSR values, the ratio of observed maximum wall deformation at a section to observe maximum wall deformation in the plane strain condition are consistent to the theoretical values.

Theoretically, wall thickness $(t)$ is an important influencing factor affecting the magnitude of the corner effects on the wall deformation. Figure 9 (b) shows the PSR-B/L-d/t relationship for each case history. Comparing Fig. 9(b) with Fig. 9(a), the general pattern or tendency is similar. The variation of wall thickness for the case histories collected in this study is limited, only $0.6 \mathrm{~m}$ to $0.8 \mathrm{~m}$.

\section{Stability Factor for Deep Excavation}

Figures 10 and 11 show the relationships between $\delta_{h \text {, max }} /$ 


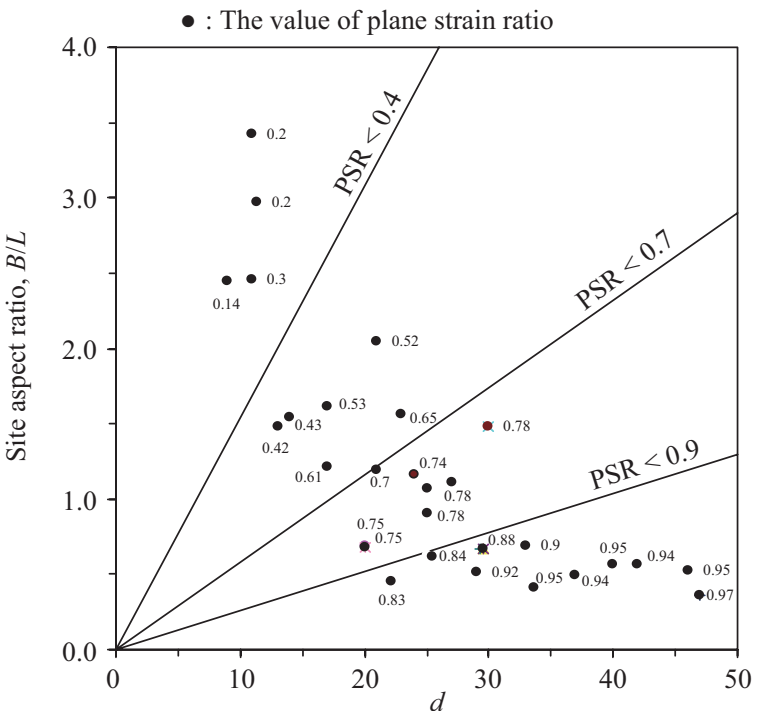

(a)

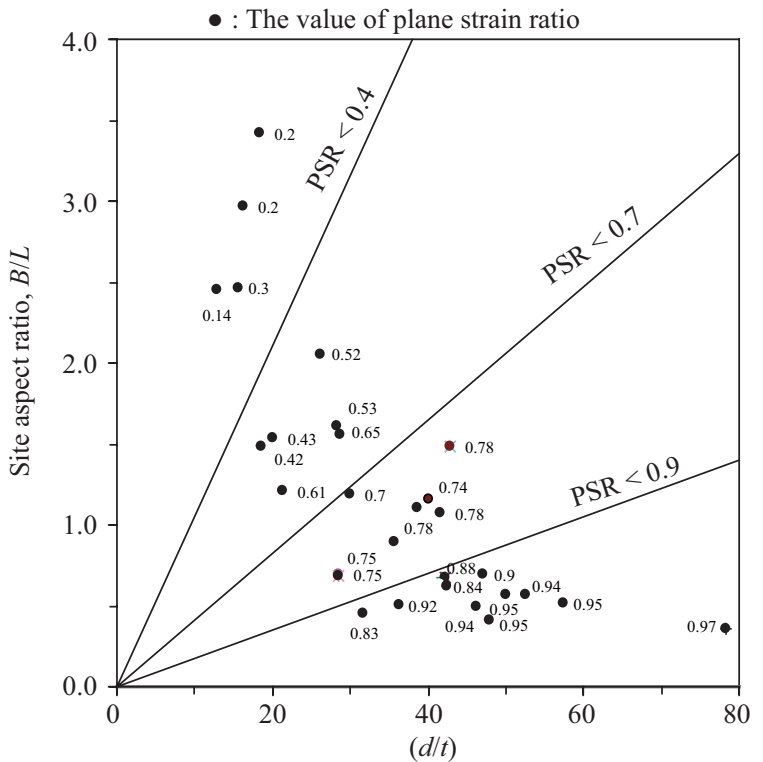

(b)

Fig. 9. (a) (PSR $-B / L-d)$ relations, (b) (PSR $-B / L-d / t)$ relations.

$\left(H-H_{e}\right)$ and $\delta_{h, \max } / H_{e}$ and the factors of safety $\left(F_{b}\right.$ and $\left.F_{p}\right)$ for overall stability, respectively. As shown in the figures, when $F_{b}$ and $F_{p}$ for overall stability approach 1.0 , the maximum wall displacement increases substantially, which may imply the excavation is on the verge of failure. Moreover, the figures also indicate that the tendency of variation between assumed hydrostatic water pressure and measured water pressure is similar. The $\delta_{h, \text { max }} /\left(H-H_{e}\right)$ has a better correlation with the $F_{b}$ or $F_{p}$ than $\delta_{h \text { max }} / H_{e}$.

Figures 10 and 11 also display that the factors of safety based on the assumed hydrostatic pressure, routinely carried by practicing engineers, are on the safe side. This is because the assumed hydrostatic water pressure is larger than the one measured in this region.

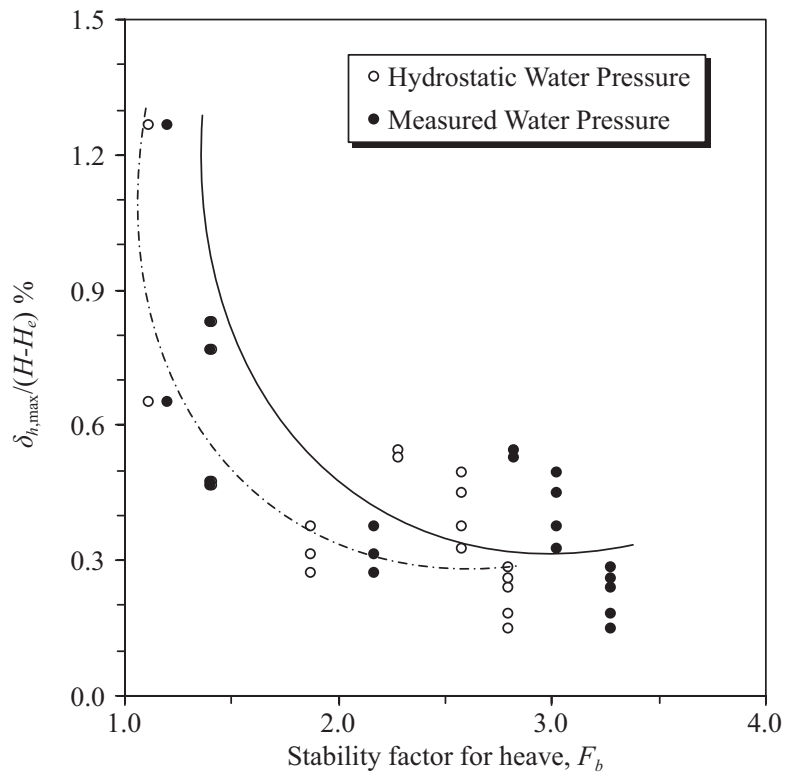

(a)

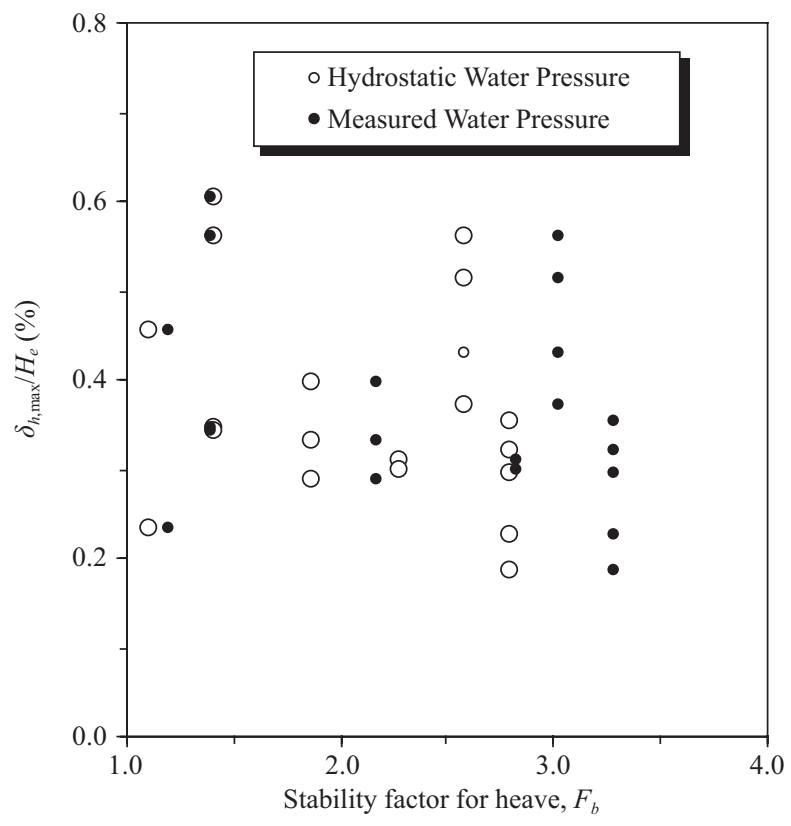

(b)

Fig. 10. Relation between the wall maximum horizontal displacement and the stability factor for heave at each excavation stage.

\section{CHARACTERISTICS OF GROUND SURFACE SETTLEMENT}

\section{Relationship Between Ground Surface Settlement and Distance to Wall}

Figure 12 shows the relationship of normalized ground surface settlement and distance from the excavation wall, with respect to the excavation depth. Also displayed in the figure for comparison are the envelopes suggested by Peck [11]. The figure also illustrates that most of the settlements fall in the 


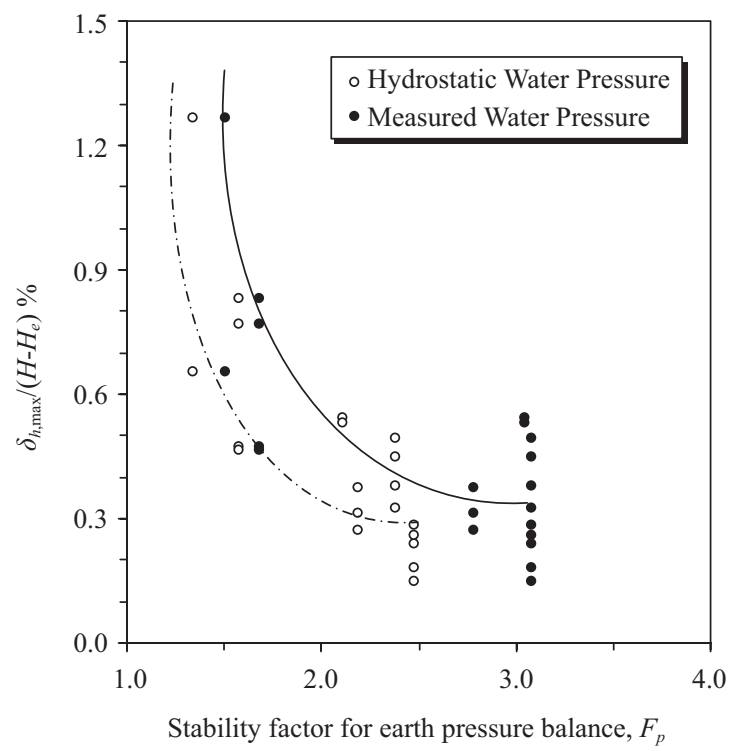

(a)

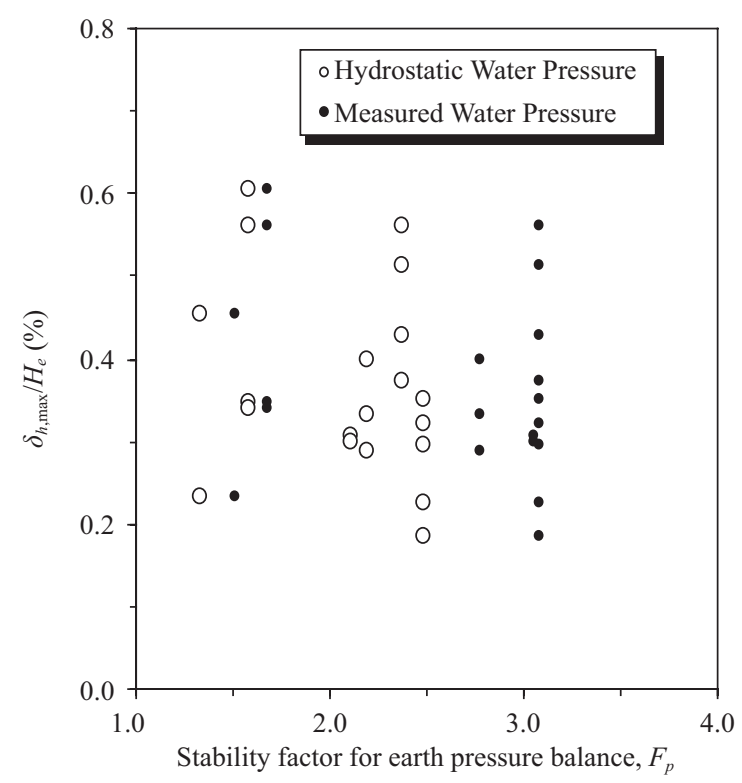

(b)

Fig. 11. Relation between the wall maximum horizontal displacement and the stability factor for earth pressure balance at each excavation stage.

range of zone II, which is classified as very soft to soft soil. Furthermore, the figure also reveals that settlements caused by the top-down method tended to be larger, compared with the extent of settlements in the top-down with bottom-up methods. This is again possibly due to the effect of soil creep for the top-down method.

\section{Relationship Between Ground Surface Settlement and Wall Deformation}

As described elsewhere, the amount of wall deformation heavily relates to ground surface settlement, and the amount of ground surface settlement closely relates to the soil property

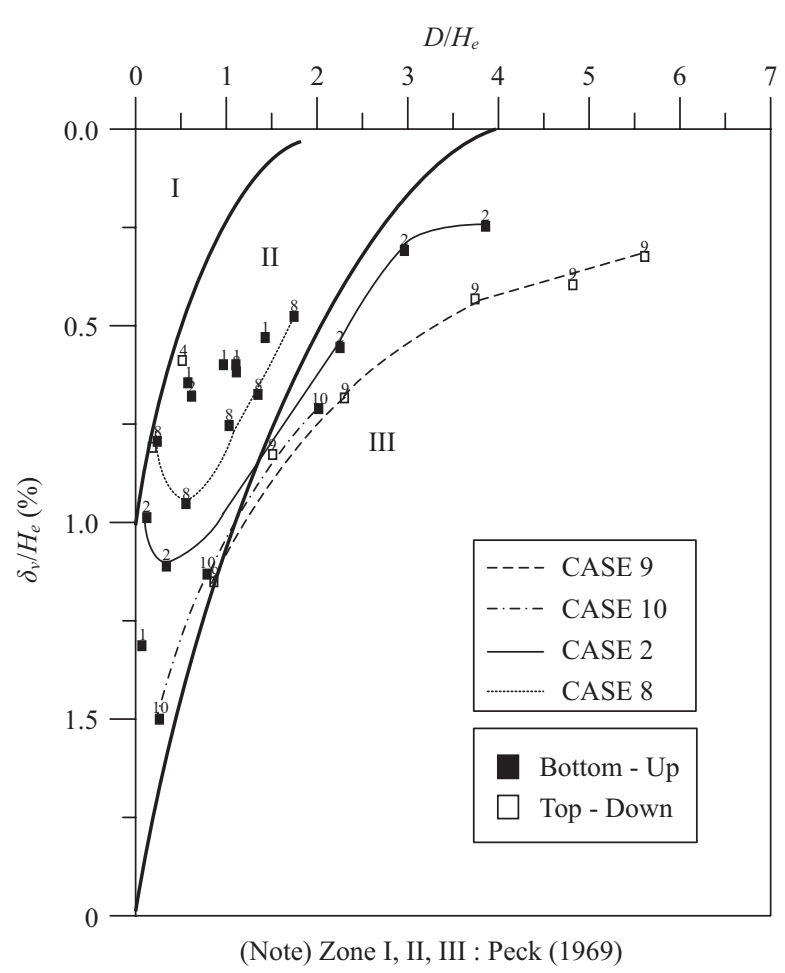

Fig. 12. $\left(\delta_{v} / H_{e}-D / H_{e}\right)$ relations.

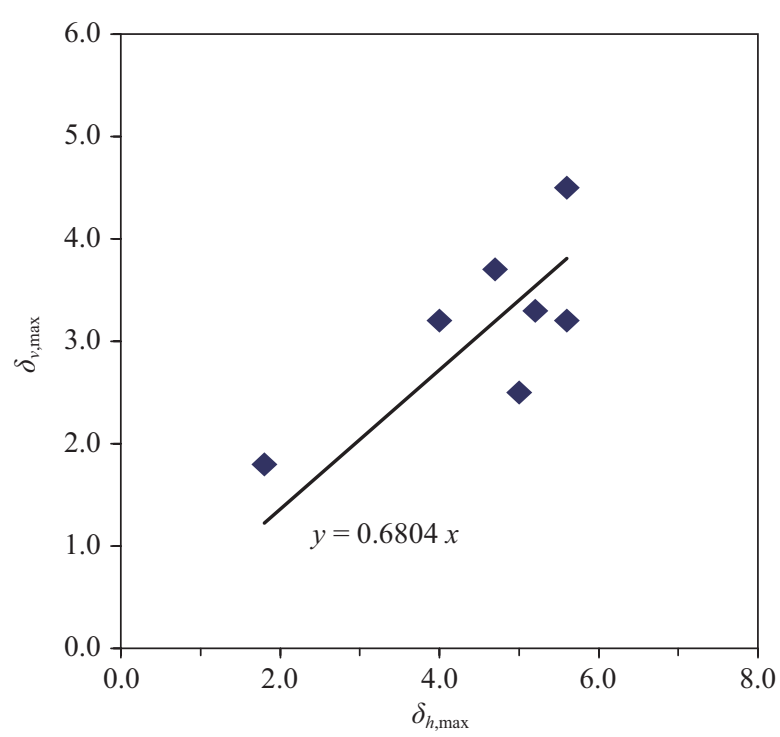

Fig. 13. $\left(\delta_{v, \max }-\delta_{h, \max }\right)$ relations.

and the distance to the wall. Many investigators, such as Clough and O'Rourke [4] and Ou et al. [8], have established the relationship between maximum wall deformation $\left(\delta_{h, \max }\right)$ and maximum ground surface settlement $\left(\delta_{v, \max }\right)$. They found that $\delta_{v, \text { max }}=(0.5 \sim 0.75) \delta_{h, \text { max }}$, and lower limit for sandy soils and upper limit for clayey soils. For very soft soils, $\delta_{v \text {,max }}$ may be equal or larger than $\delta_{h, \max }$. Figure 13 shows that the Taipei $\mathrm{T} 2$ zone, which in nature is a layered sandy and clayey soil deposit, $\delta_{v, \text { max }}$ and is about equal to $0.68 \delta_{h, \max }$. 


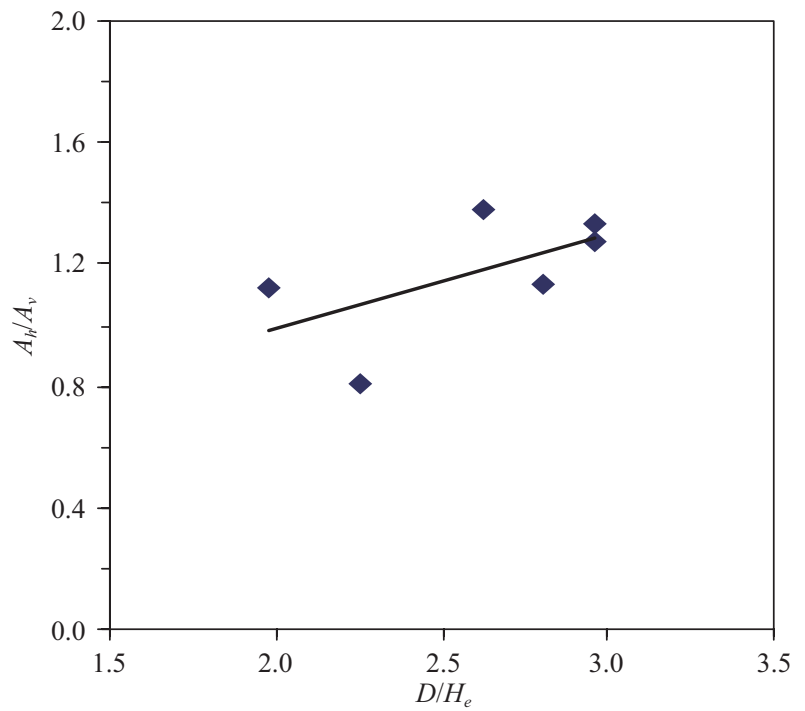

Fig. 14. The normalization of wall deformations and ground settlement area.

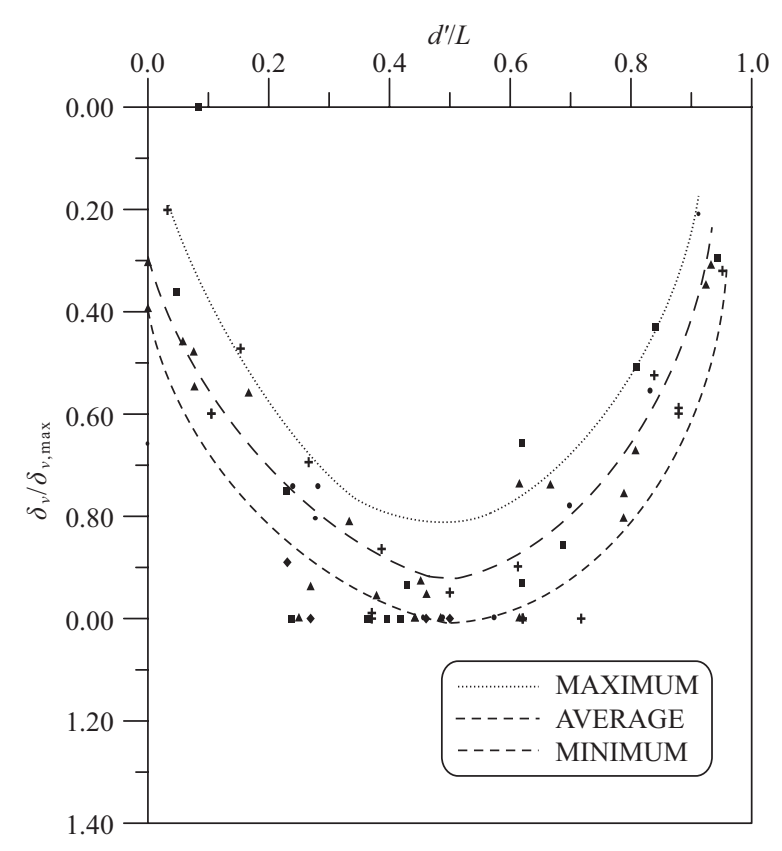

Fig. 15. $\left(\delta_{v} / \delta_{v, \max }-d^{\prime} / L\right)$ relations.

Under the undrained condition, the area of wall deformation is approximately equal to that of surface settlement. Figure 14 illustrates the relationship of wall deformation and ground surface settlement for layered sandy soil and clayey soil deposits as the stratum in the $\mathrm{T} 2$ zone, ratios of the areas of wall deformation $\left(A_{h}\right)$ to those of ground surface settlement $\left(A_{v}\right)$ for some case histories. The figure also shows that ratio of $A_{v} / A_{h}$ is about $0.8-1.3$, with an average of 1.18 . The area of soil settlements in the adjacent areas to the excavation sites is approximately equal to the area of the inward movement of wall deformations, even in layered sandy soil and clayey soil deposits.

\section{Relationship Between Ground Surface Settlement and Distance to Corner}

Generally, settlement measurement points are allocated along the walls surrounding excavation sites. In this study, case histories having settlement measurement points parallel to the peripheral walls were analyzed. Figure 15 shows the connection between $d / L$ and $\delta_{v} / \delta_{v, \max , L}$, in which $d$ denotes distance to the corner, $L$ length of the wall, $\delta_{v}$ settlement at a distance of $d$, $\delta_{v, \max , L}$ maximum settlement in a direction of wall length (parallel to the excavation border).

In Fig. 15, the amount of ground surface settlement is affected by the corner effect, the closer to a plane strain condition a settlement measurement point is (being farther from the corner), the larger the amount of ground surface settlement that will occur. Therefore, in most cases, the maximum ground surface settlement took place at the approximate middle position of the wall, and settlements in corner positions were comparatively smaller due to the arching effect with a magnitude of $20 \%-60 \%$ of the maximum settlement.

\section{Ground Surface Settlement Envelope}

According to the studies by Ou et al. [7, 8], ground surface settlements are of two types: (1) Concave type and (2) Spandrel type. In either type, the settlement trough consists of a primary influence zone and a secondary influence zone. The slope of the settlement curve in the primary zone is steep, and more heavily influences adjacent buildings. Meanwhile, the slope of the settlement curve in the secondary zone is relatively flat, and has a minor influence to buildings.

Clough and O'Rourke [4] also suggested different settlement envelopes for various geological conditions by using $D / H_{e}$ as the horizontal coordinate and $\delta_{v} / \delta_{v, \max }$ as the vertical coordinate.

Figure 16 illustrates values of the plotted case histories for establishing a suitable settlement envelope using the parameters as suggested by Clough and O'Rourke [4]. The figure also shows the envelope suggested by Bowles [1] for comparison. The envelopes suggested either by Clough and O'Rourke [4] or Bowles [1] may not be applicable in our case histories. However, through the scattering of the observation points, in the Taipei T2 zone the primary ground surface settlement lies within a distance of two times the excavation depth, and the secondary ground surface settlement lies within a distance of 2 to 3 times the excavation depth. Figure 16 shows in solid lines that by combining all the observation data, the approximate settlement envelope for the T2 zone of the Taipei Basin is established.

\section{ESTABLISHMENT OF A FORECAST MODEL FOR WALL DEFORMATION AND GROUND SURFACE SETTLEMENT}

By employing charts, this study provides a simple and easy ways for engineers to estimate the wall deformation and 


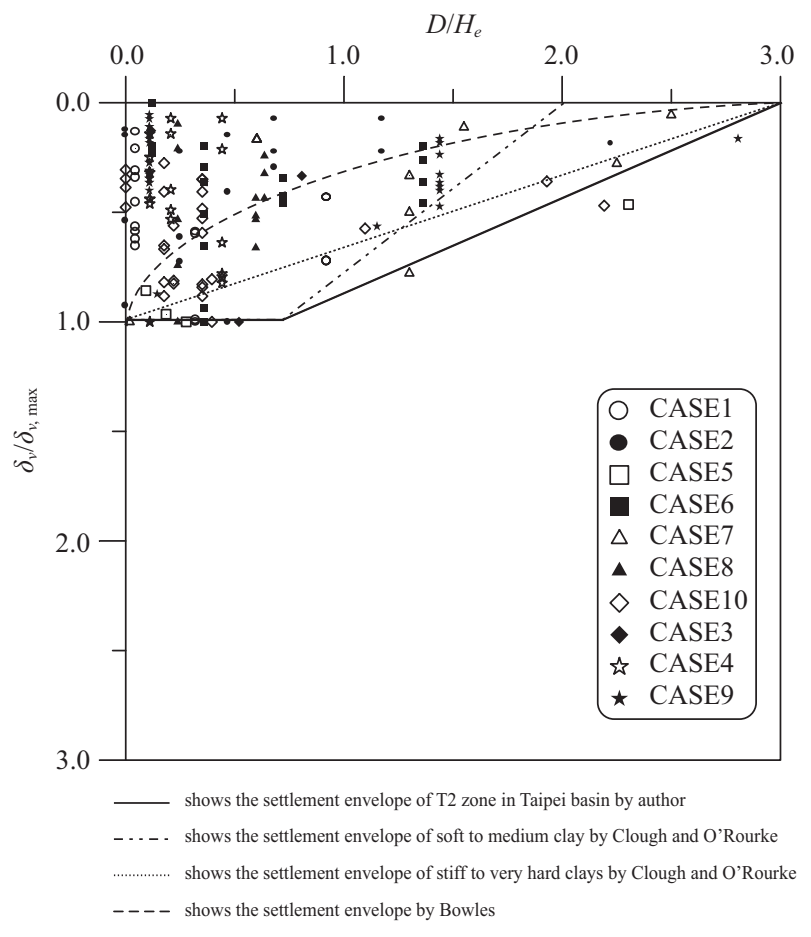

Fig. 16. The normalization of the ground surface settlement [14].

ground surface settlement for excavations affected by corners in a soil similar to the Taipei T2 zone, which naturally is a layered sandy and clayey soil deposit. The procedure is described as follows.

\section{(I) To determine the wall deformation}

1. Calculate the aspects of safety of the excavation for overall stability, $F_{b}$ and $F_{p}$.

2. Estimate the maximum wall displacement in the center section of the excavation $\left(\delta_{h, \text { max }}\right)$ utilizing the empirical charts, such as Figs. 10(a) and 11(a), or the numerical method, such as the beam on elastic foundation method or finite element method.

3. Determine the plane strain ratio (PSR) for a section affected by corners by referring to Fig. 9 (b) based on the values of $B, L, d$ and $t$. Then by employing $\delta_{p s}$ as equal to $\delta_{h \text {,max }}$ derived from the above step and the definition equation PSR $=\delta_{h} / \delta_{p s}, \delta_{h}$ can thus be derived, where $\delta_{h}$ is the maximum wall displacement of the section with a distance $d$ to the corner.

(II) To determine ground surface settlement

1. Estimate the maximum ground surface settlement $\left(\delta_{v, \max }\right)$ with the assistance of Fig. 13 based on the value of $\delta_{h, \max }$. Figure 14 is also applicable as long as an appropriate function for settlement trough is specified.

2. Compute the settlement $\left(\delta_{v}\right)$ at the various distances $\mathrm{d}$ from the wall utilizing the envelope suggested by the authors in this study (Fig. 16).
Setting $d$ as the position for analyzing the ground surface settlement, together with $L$ and $\delta_{v, \max }$, by using Fig. 15, the ground surface settlement $\delta_{v}$ of other cross section positions (not the centerline cross section) can be deduced, and thus, furnish the correction to the ground surface settlement caused by the corner effect.

\section{CONCLUSION}

1. The maximum wall deformation induced by excavation for each excavation stage is approximately $0.2 \%-0.5 \%$ the excavation depth for the sections near the excavation center, i.e., in the plane strain condition. Based on our studies, the wall deformation at a section relates to excavation depth and the distance to the corner. Carrying out the prediction of wall deformation or ground surface settlement may require to consider the corner effect of the excavation.

2. This study establishes preliminary relationships between the ground surface settlement and the distance to the corner. The maximum ground surface settlement takes place near the center of the excavation; and settlements at the corners are smaller due to the arching effect, they are generally $20 \%-60 \%$ of the maximum settlement.

3. According to the results of the excavation case study of the analyzed area: the area within a distance of two times the excavation depth is the primary influenced settlement area. Meanwhile, that at a distance of 2-3 times of the excavation depth is the secondary influenced settlement area.

4. A similar tendency exists for the relationship between $\delta_{h, \text { max }} / H_{e}$ and the factors of safety against basal heave or push-in failure with the assumption of hydrostatic pressure or measured water pressure. A similar tendency of a larger factor of safety for a deeper embedment depth was found, and this is even more distinct when $\delta_{h, \max } /\left(H-H_{e}\right)$ is below $0.5 \%$.

5. The proposed simple and easy-to-use evaluation of excavation hazard analysis provides a design approach for working in layered sandy and clayey soil deposits, such as the Taipei area.

\section{REFERENCES}

1. Bowles, J. E., Foundation Analysis and Design, 4th Ed., McGraw-Hill Book Company, New York, U.S.A. (1986).

2. Caqout, A. and Kerisel, J., Triate de Méchanique des Sols, Gauthier-Villars, Paris (1949).

3. Cheng, T. Y., Geotechnical Characteristics of Sungshan Formation within Taipei City, Master's Thesis, Asian Institute of Technology, Thailand (1987).

4. Clough, G. W. and O'Rourke, T. D., "Construction-induced movements of insitu wall," In Proceedings of the Geotechnical Special Conference, No. 25, Design and Performance of Earth Retaining Structure, ASCE, Ithaca, pp. 439-470 (1990).

5. Hulme, T. W., Potter, L. A. C., and Shirlaw, J. N., Singapore Mass Rapid Transit System, Construction, Proceedings Institution of Civil Engineering, Part 1, August (1989).

6. Mana, A. I. and Clough, G. W., "Prediction of movements for braced cut 
in clay," Journal of the Geotechnical Engineering Division, ASCE, Vol. 107, No. 6, pp. 759-777 (1981).

7. Ou, C. Y., Chiou, D. C., and Wu, T. S., "Three dimensional finite element analysis of deep excavations," Journal of Geotechnical Engineering, ASCE, Vol. 122, No. 5, pp. 337-345 (1996).

8. Ou, C. Y., Hsieh, P. G., and Chiou, D. C., "Characteristics of ground surface settlement during excavation," Canadian Geotechnical Journal, Vol. 30, No. 5, pp. 758-767 (1993).

9. Ou, C. Y. and Hu, M. Y., Stability Analysis of Excavations in Clay, Geotechnical Research Report No. 99007, Department of Construction Engineering, National Taiwan University of Science and Technology, Taipei, Taiwan, R.O.C., (1998).

10. Padfield, C. J. and Mair, R. J., Design of Retaining Walls Embedded in Stiff Clay, CIRIA Report, England, No. 104, pp. 83-84 (1984).

11. Peck, R. B., "Deep excavation and tunneling in soft ground," Proceedings of seventh International Conference on Soil Mechanics and Foundation Engineering, State-of-the-Art Volume, Mexico City, pp. 225-290 (1969).

12. Terzaghi, K., Theoretical Soil Mechanics, John Wiley and Sons, Inc., New York (1943)

13. Woo, S. M. and Moh, Z. C., "Geotechnical characteristics of soils in Taipei Basin," In Proceedings of the 10th Southeast Asian Geotechnical Conference, Special Taiwan Session, Taipei, pp. 51-65 (1990).

14. Wu, C. H. and Ou, C. Y., "Wall deflection and ground surface settlement induced by deep excavation in the Taipei T2 zone," Journal of Chinese Institute of Civil and Hydraulic Engineering, Vol. 12, No. 3, pp. 499-510 (2000).

15. Wu, W. T., "Geotechnical engineering characteristics of soils in relation to horizontal zoning in Taipei Basin," Abstract of Articles Sino-Geotechnics, No. 22, June, pp. 5-27 (1988). 